\title{
Prone transradial catheterization for combined single-session endovascular and percutaneous interventions: approach, technical success, safety, and outcomes in 15 patients
}

\author{
Rajiv N. Srinivasa $\oplus$ \\ Jeffrey Forris Beecham Chick (1) \\ Joseph J. Gemmete (1) \\ Bill S. Majdalany (1) \\ Anthony Hage (1) \\ Alex Jo (1) \\ Ravi N. Srinivasa (1)
}

\begin{abstract}
PURPOSE
We aimed to report approach, safety, technical success, and clinical outcomes of prone transradial access (PTRA) and demonstrate feasibility for procedures requiring simultaneous arterial intervention and prone percutaneous access.
\end{abstract}

\section{METHODS}

Fifteen patients underwent PTRA, seven females (47\%) and eight males (53\%), mean age of 55 years (range, 19-78 years). All patients underwent PTRA for combined transarterial and posterior-approach percutaneous interventions. Variables included sheath size (French, F), type of anesthesia, arterial intervention technical success, posterior-approach percutaneous intervention technical success, estimated blood loss $(\mathrm{mL})$, fluoroscopy and procedure time, complications, and follow-up.

\section{RESULTS}

Mean sheath size was $4 \mathrm{~F}$ (range, 4-6 F; SD $=0.5$ ). Arterial interventions included transarterial embolization of renal $(n=6)$, hepatic $(n=2)$, and pelvic vessels $(n=2)$, diagnostic arteriography $(n=4)$, and embolization of an arteriovenous malformation $(n=1)$. Posterior-approach intervention technical success was $100 \%$ (15/15). PTRA technical success was 100\% (15/15). Posterior-approach percutaneous interventions included retroperitoneal $(n=5)$ and pelvic $(n=1)$ mass biopsies, nephrostomy tube placement $(n=2)$, cryoablation of pelvic $(n=2)$ and renal $(n=1)$ masses, sclerotherapy of arteriovenous malformations $(n=2)$, foreign body removal from the renal collecting system $(n=2)$, ablation of a renal tumor $(n=1)$, intracavitary injection of pulmonary mycetoma $(n=1)$, and ablation and cementoplasty of a vertebral body tumor $(n=1)$. The biopsies were diagnostic (6/6). There were no minor or major access-site complications.

\section{CONCLUSION}

PTRA is a safe and feasible method for performing combined arterial and posterior approach percutaneous interventions without the need for repositioning.
From the Division of Vascular and Interventional Radiology, Department of Radiology (R.N.S. $\square$ medravi@gmail.com, J.F.B.C., J.J.G., B.S.M., A.H., A.J., Rajiv.N.S.), University of Michigan Health Systems, Ann Arbor, Michigan, USA; Department of Radiology (A.H.), University of Michigan Medical School, Ann Arbor, Michigan, USA.

Received 4 February 2018; revision requested 26 February 2018; last revision received 22 March 2018; accepted 13 April 2018.

DOI 10.5152/dir.2018.18050 upine transradial access (TRA) was first described as a novel approach for performing coronary arteriography (1). Since its inception, a myriad of noncoronary applications for TRA have emerged allowing for shortened patient recovery times, decreased hospital costs, and improved patient satisfaction $(2,3)$. Additionally, multiple randomized prospective studies have demonstrated the benefits of TRA as an alternative to transfemoral access in reducing access-site related complications (4-6).

Supine TRA has been utilized for chemoembolization, radioembolization, uterine artery embolization, aortoiliac and peripheral arterial interventions as well as other renal and visceral interventions (7-11). The efficacy and safety of supine TRA has been well established in large patient populations and across a wide range of vascular interventions with a high rate of technical success and safety $(11,12)$. However, these prior reports only describe TRA with standard supine patient positioning. This standard technique is limited in that it does not allow the operator to perform combined procedures requiring simultaneous endovascular and percutaneous access from a posterior-approach.

Oncologic interventions such as transarterial embolization with concomitant percutaneous ablation for retroperitoneal and pelvic tumors may require both arterial access and

You may cite this article as: Srinivasa RN, Chick JFB, Gemmete JJ, et al. Prone transradial catheterization for combined single-session endovascular and percutaneous interventions: approach, technical success, safety, and outcomes in 15 patients. Diagn Interv Radiol 2018; 24:276-282. 
posterior percutaneous-approach access. In such cases, repositioning the patient mid-procedure from supine to prone or vice versa is cumbersome and time consuming and may place the patient at greater risk for procedural complications. Prone transradial access (PTRA) with combined posterior-approach percutaneous ablation has been previously described for these instances (13).

The purpose of this study is to describe the approach, technical success, and safety of PTRA in combination with a variety of posterior-approach interventions. This technique facilitates complex single-session endovascular and percutaneous procedures without the need for repositioning.

\section{Methods}

\section{Patient identification}

Institutional review board approval (HUM00120582) was obtained and this retrospective study complied with the Health Insurance Portability and Accountability Act. Informed consent was obtained from all patients. All patients undergoing PTRA for combined endovascular and percutaneous posterior-approach interventions $(n=15)$ were identified via retrospective review of the electronic medical record (EPIC; Epic Systems Corporation) in conjunction with the department's prospectively maintained database (Microsoft Access 2017). Three $(21 \%)$ patients were included in a prior report describing the prone transradial technique for simultaneous embolization and cryoablation of solid neoplasms (13).

\section{Patient demographics}

Patients included 15 individuals, eight males (53\%) and seven females (47\%), with

\section{Main points}

Prone transradial access is feasible due to the ability to rotate the forearm at the elbow, allowing for easy access to the radial artery in the prone position.

Procedures that must be performed in the prone position, such as nephrostomy tubes, and percutaneous ablation procedures can be performed along with arteriography simultaneously without repositioning the patient.

Treatment of posteriorly located arteriovenous malformations can be facilitated by allowing simultaneous percutaneous and transarterial approaches. a mean age of 55 years (range, $19-78$ years). All patients underwent PTRA for combined endovascular and percutaneous interventions.

\section{PTRA technique}

TRA access and PTRA have been previously described $(13,14)$. All patients were evaluated by an attending interventional radiologist in the hospital, emergency department, or clinic before the procedure. All procedures were performed using monitored anesthesia care or general anesthesia administered by an attending anesthesiologist. PTRA procedures were performed by one of four attending interventional radiologists with 2 years, 6 years $(n=2)$, and 20 years of experience.

Before all procedures, a Barbeau test was performed on the left wrist to confirm that redundant arterial supply was present. $\mathrm{Pa}$ tients with Barbeau A, B, or C physiology were deemed safe to proceed with PTRA, while patients with Barbeau D physiology were deemed unsafe for PTRA $(14,15)$. Topical lidocaine (Fougera Pharmaceuticals) and nitroglycerin ointment (Fougera Pharmaceuticals) were then applied to the skin over the radial artery 30 minutes prior to the start of the procedure. The patients were brought to the angiography suite and placed in prone position with the left arm abducted $25^{\circ}$ and the hand in a supine position. Under ultrasound-guidance, subcutaneous nitroglycerin $100 \mu \mathrm{g}$ (American Regent) and 2\% lidocaine $9 \mathrm{~mL}$ (Baxter) were injected into the tissues surrounding the radial artery. The radial artery was then accessed using a 21-gauge micropuncture needle (Cook Medical) through which a 0.018-inch guidewire was placed. A $4 \mathrm{~F}$ transitional dilator (Cook Medical) was then placed and the wire was exchanged for a 0.035 -inch J-wire and a 4 F, 5 F, or $6 \mathrm{~F}$ Glidesheath slender (Terumo Interventional Systems) sheath was inserted into the artery. A cocktail consisting of nitroglycerin $200 \mu \mathrm{g}$ (American Regent), heparin 3000 units (APP Pharmaceuticals), and verapamil $2.5 \mathrm{mg}$ (Hospira) was then injected through the side port of the sheath after hemodilution to a total volume of $20 \mathrm{~mL}$.

All procedures utilizing PTRA were performed in a hybrid angiography suite using an Artis Zee interventional angiography system (Siemens Medical), SOMATOM
Definition AS computed tomography (CT) (Siemens Medical), and when needed EPIQ ultrasound (Philips Medical).

At the conclusion of each procedure, the PTRA sheath was removed and a TR band (Terumo Interventional Systems) was placed over the access site in the left wrist. The TR band was inflated with $18 \mathrm{~mL}$ of air initially and slowly deflated to ensure patent hemostasis with preservation of a waveform on pulse oximetry. After 20 minutes, 2 $\mathrm{mL}$ of air was removed, followed by $2 \mathrm{~mL}$ of air every 10 minutes until the band was completely deflated.

\section{Variables, definitions, and outcomes}

Barbeau physiology, sheath size, anesthesia type, percutaneous posterior-approach intervention technical success, PTRA technical success, type of percutaneous posterior-approach intervention, type of arterial intervention, contrast volume, estimated blood loss volume, fluoroscopy and procedure time, and complications were recorded.

PTRA technical success was defined as insertion of the transradial sheath into the artery with the patient in prone position. Arterial technical success was defined as either successful embolization of the targeted artery or completion arteriography of the desired vessel. Percutaneous posterior-approach intervention technical success was defined as successful completion of the posterior-approach intervention. Contrast volume was recorded in milliliters. Estimated blood loss was recorded in milliliters. Procedure time was recorded in minutes. Complications were classified based on the Society of Interventional Radiology (SIR) quality improvement guidelines for the reporting and archiving of interventional radiology procedures $(16,17)$. Follow-up was recorded in days.

\section{Statistical analysis}

Descriptive statistics were provided as means, standard deviations (SD), percentages, and ranges. The analyses were conducted using SPSS Version 24 (IBM Corporation).

\section{Results}

A total of 15 cases utilizing PTRA were performed. Of the patients, $13(87 \%)$ had Barbeau A physiology and 2 (13\%) had Barbeau $B$ physiology. Mean sheath size was 
4 $\pm 0.5 \mathrm{~F}$ (range, 4-6 F). Of the procedures, 11 (73\%) were performed under general endotracheal anesthesia and 4 (27\%) under monitored anesthesia care. All (100\%) posterior approach interventions and all (100\%) PTRA interventions were technically successful.

Patient demographics, type of arterial and posterior-approach interventions are shown in the Table. Fig. 1 illustrates PTRA

Table. Patient demographics and interventions performed

\begin{tabular}{|c|c|c|c|}
\hline Patient & $\begin{array}{l}\text { Age (years)/ } \\
\text { Gender }\end{array}$ & Arterial intervention & $\begin{array}{l}\text { Posterior percutaneous } \\
\text { intervention }\end{array}$ \\
\hline 1 & $35 / F$ & $\begin{array}{l}\text { Transarterial embolization of renal } \\
\text { angiomyolipoma }\end{array}$ & Renal mass biopsy \\
\hline 2 & $66 / M$ & $\begin{array}{l}\text { Transarterial chemoembolization } \\
\text { of hepatocellular carcinoma }\end{array}$ & Adrenal mass biopsy \\
\hline 3 & $78 / \mathrm{M}$ & Renal cell carcinoma embolization & $\begin{array}{l}\text { Cryoablation of renal mass, and } \\
\text { contralateral renal mass biopsy }\end{array}$ \\
\hline 4 & $37 / F$ & Lower extremity arteriogram & $\begin{array}{l}\text { Sclerotherapy of calf venous } \\
\text { malformation }\end{array}$ \\
\hline 5 & $65 / M$ & Renal arteriogram & $\begin{array}{l}\text { Nephroscopic foreign body } \\
\text { retrieval of coils eroded into } \\
\text { renal collecting system and } \\
\text { nephro-ureteral stent placement }\end{array}$ \\
\hline 6 & $75 / \mathrm{M}$ & $\begin{array}{l}\text { Transarterial embolization of } \\
\text { presacral sarcomatoid carcinoma }\end{array}$ & $\begin{array}{l}\text { Cryoablation of presacral } \\
\text { sarcomatoid carcinoma and } \\
\text { percutaneous nephrostomy } \\
\text { placement }\end{array}$ \\
\hline
\end{tabular}

$7 \quad 45 / F \quad$ Transarterial embolization of pelvic malignant peripheral nerve sheath tumor

\begin{tabular}{lll}
8 & $62 / \mathrm{M}$ & $\begin{array}{l}\text { Embolization of pelvic } \\
\text { arteriovenous malformation }\end{array}$ \\
\hline 9 & $54 / \mathrm{F}$ & Intercostal arteriogram \\
\hline
\end{tabular}

47/F Lumbar arteriogram

11

19/M Iliac arteriogram

$12 \quad 55 / F \quad$ Renal arteriogram and embolization

\begin{tabular}{|c|c|c|}
\hline 13 & $65 / F$ & $\begin{array}{l}\text { Transarterial chemoembolization } \\
\text { of hepatocellular carcinoma }\end{array}$ \\
\hline 14 & $56 / M$ & $\begin{array}{l}\text { Transarterial embolization of renal } \\
\text { mass }\end{array}$ \\
\hline 15 & $66 / M$ & $\begin{array}{l}\text { Transarterial embolization of renal } \\
\text { mass }\end{array}$ \\
\hline
\end{tabular}

Bilateral percutaneous nephrostomy placement

Intracavitary antifungal injection of lower lobe mycetoma

Radiofrequency ablation and cementoplasty of $L 4$ cystic lesion

Sclerotherapy of pelvic arteriovenous malformation

Nephroscopic foreign body retrieval of coils eroded into renal collecting system

Pelvic mass biopsy

Renal mass biopsy

Renal mass biopsy and microwave ablation

F, female; $M$, male.

$(n=1)$, TAE of presacral sarcomatoid carcinoma $(n=1)$, TAE of pelvic malignant peripheral nerve sheath tumor $(n=1)$, TAE of a pelvic arteriovenous malformation $(n=1)$, intercostal artery arteriogram $(n=1)$, lumbar artery arteriogram $(n=1)$, and iliac artery arteriogram $(n=1)$ (Fig. 4). Posterior-approach percutaneous interventions performed in the 15 patients included biopsy of a renal mass $(n=3)$, biopsy of an adrenal mass $(n=1)$ (Fig. 3), biopsy and cryoablation of a renal mass $(n=1)$, microwave ablation of a renal mass $(n=1)$, sclerotherapy of a venous malformation in the calf $(n=1)$, foreign body retrieval of coils from the renal collecting system followed by placement of a nephro-ureteral stent $(n=1)$, cryoablation of a presacral sarcomatoid carcinoma with concomitant percutaneous nephrostomy placement $(n=1)$, cryoablation of a pelvic malignant peripheral nerve sheath tumor $(n=1)$, bilateral nephrostomy placement $(n=1), C T$-guided intracavitary injection of an antifungal agent into a lower lobe myectoma $(n=1)$, radiofrequency ablation (RFA) and cemen-

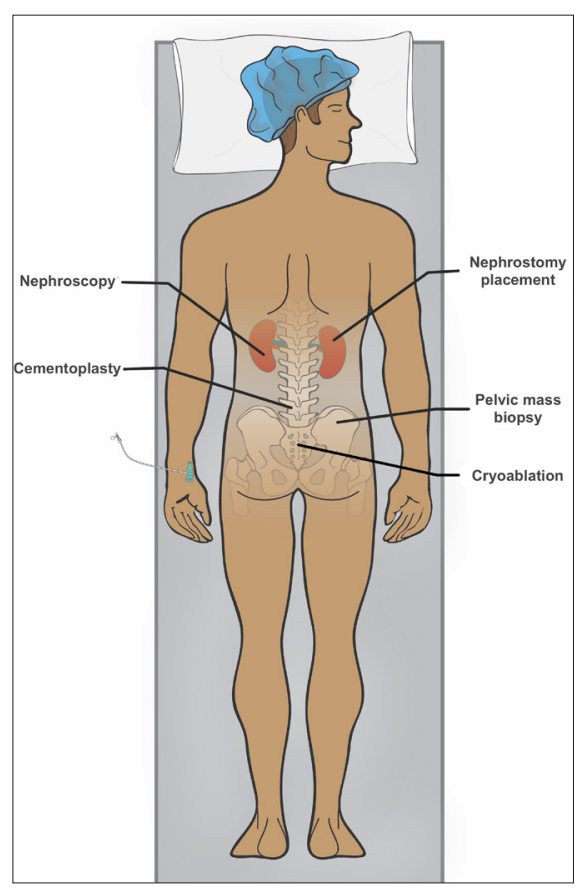

Figure 1. Schematic illustration of prone transradial access technique. Since the forearm is flexible at the elbow, access into the radial artery is relatively simple even in the prone position. Arteriography can be performed in conjunction with other procedures requiring prone positioning including but not limited to nephrostomy tube placement, percutaneous nephroscopy, vertebral cementoplasty, pelvic mass biopsy, and pelvic mass cryoablation. 

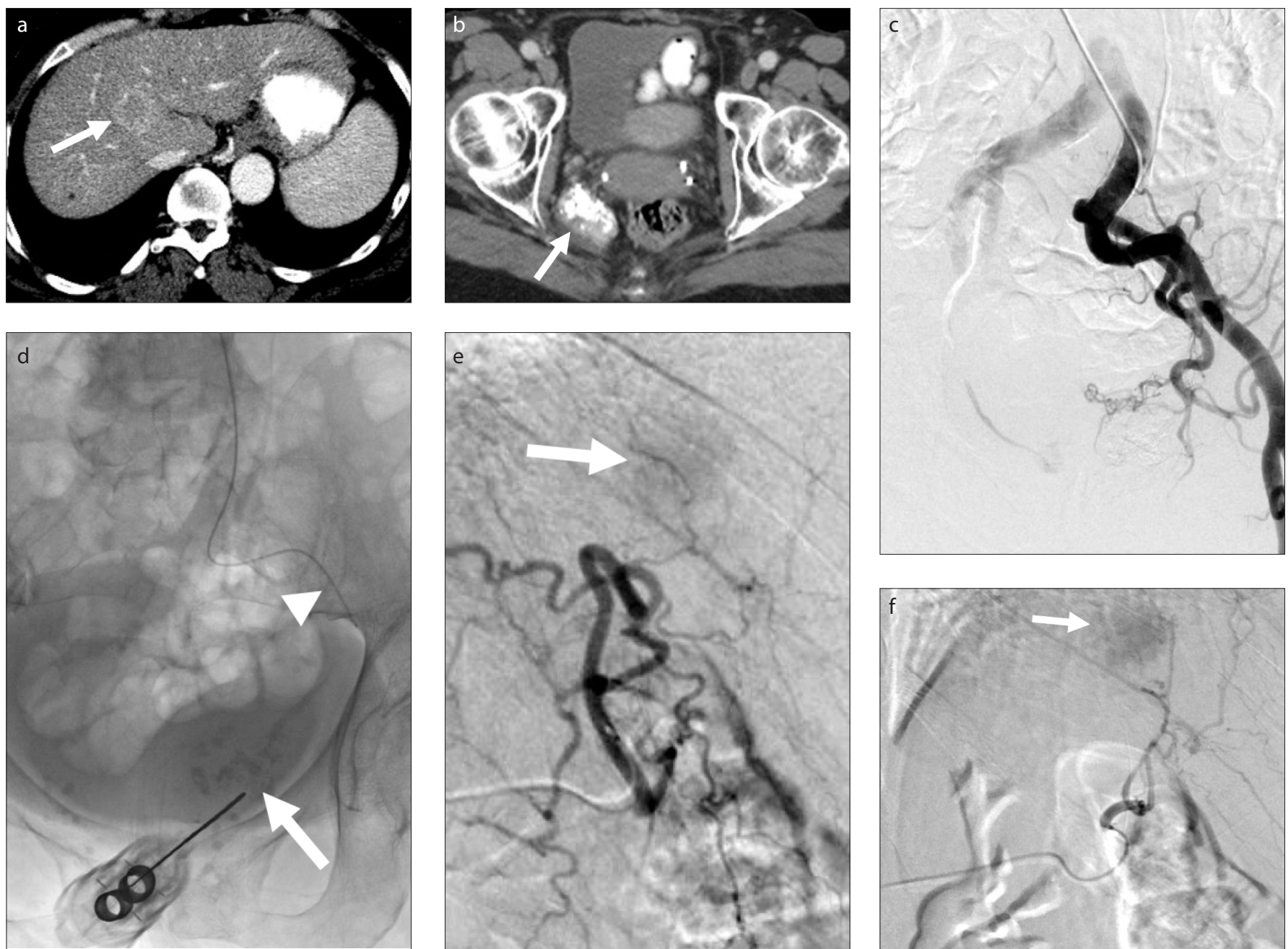

Figure 2. a-f. A 65-year-old female with history of hepatocellular carcinoma and an indeterminate right pelvic mass. Axial CT image (a) through the liver demonstrates a hypervascular mass in the right hepatic lobe (arrow). Axial CT image (b) through the pelvis demonstrates a solid and calcified mass within the right pelvis (arrow) of indeterminate etiology. There was question whether this represented a fibrous tumor versus a vascular malformation. Prone transradial arteriography (c) demonstrates no evidence for arterial supply to the mass. Delayed imaging also demonstrated no venous filling to suggest a venous malformation. Fluoroscopic image (d) demonstrates a biopsy needle entering from a US-guided posterior percutaneous approach (arrow). A wire is seen within the artery as well (arrowhead). Subselective hepatic arteriography $(\mathbf{e}, \mathbf{f})$ in the prone position reveals the hypervascular mass within the liver (arrows) prior to chemoembolization.

toplasty of a vertebral body lesion $(n=1)$, percutaneous access of a pelvic sidewall arteriovenous malformation and embolization ( $n=1$ ) (Fig. 4), foreign body retrieval of coils from the renal collecting system $(n=1)$, and ultrasound-guided pelvic mass biopsy ( $n=1$ ) (Fig. 2).

Arterial intervention technical success was $100 \%(15 / 15)$. Posterior-approach intervention technical success was $100 \%$ $(15 / 15)$. The biopsies that were performed were diagnostic $(100 \%, 6 / 6)$ and showed renal angiomyolipoma in patient 1 , adrenal adenoma in patient 2 , renal cell carcinoma in patient 3 , solitary fibrous tumor in patient 13 , and renal cell carcinoma in patient 14 .

Mean contrast volume was $87 \pm 65.9 \mathrm{~mL}$ (range, 10-275 mL). Mean estimated blood loss was $34 \pm 74.8 \mathrm{~mL}$ (range, $1-300 \mathrm{~mL}$ ). Mean procedure time was $167 \pm 62 \mathrm{~min}$ (range, 61-301 min). Mean fluoroscopy time was $29 \pm 16.4 \mathrm{~min}$ (range, 6-71 $\mathrm{min}$ ). Mean follow-up was 169 days (range, 38356 days).

There were no minor or major complications directly related to PTRA (16). Patient 2 (TACE and adrenal mass biopsy) developed spontaneous bacterial peritonitis requiring antibiotic therapy. Patient 4 (lower extremity arteriogram and percutaneous sclerotherapy) reported significant calf pain one week following the procedure which was relieved with nonsteroidal antiinflammatory medication. Patient 5 (renal arteriogram and nephroscopic foreign body removal) developed fever and leukocytosis one day after foreign body retrieval and required antibiotic therapy. Patient 6 (TAE and cryoablation of sarcomatoid carcinoma) developed sepsis requiring intensive care unit admission one day following the procedure. Patient 9 (intercostal arteriogram and antifungal injection into a mycetoma) developed a small expanding postprocedural pneumothorax requiring chest tube placement. Patient 10 (lumbar arteriogram and RFA and cementoplasty of an L4 cystic lesion) had persistent back pain following the procedure. Lastly, patient 12 (renal arteriogram and nephroscopic foreign body removal) developed arterial extravasation following coil removal from the renal collecting system and required glue embolization of a lower pole segmental renal arterial branch. 

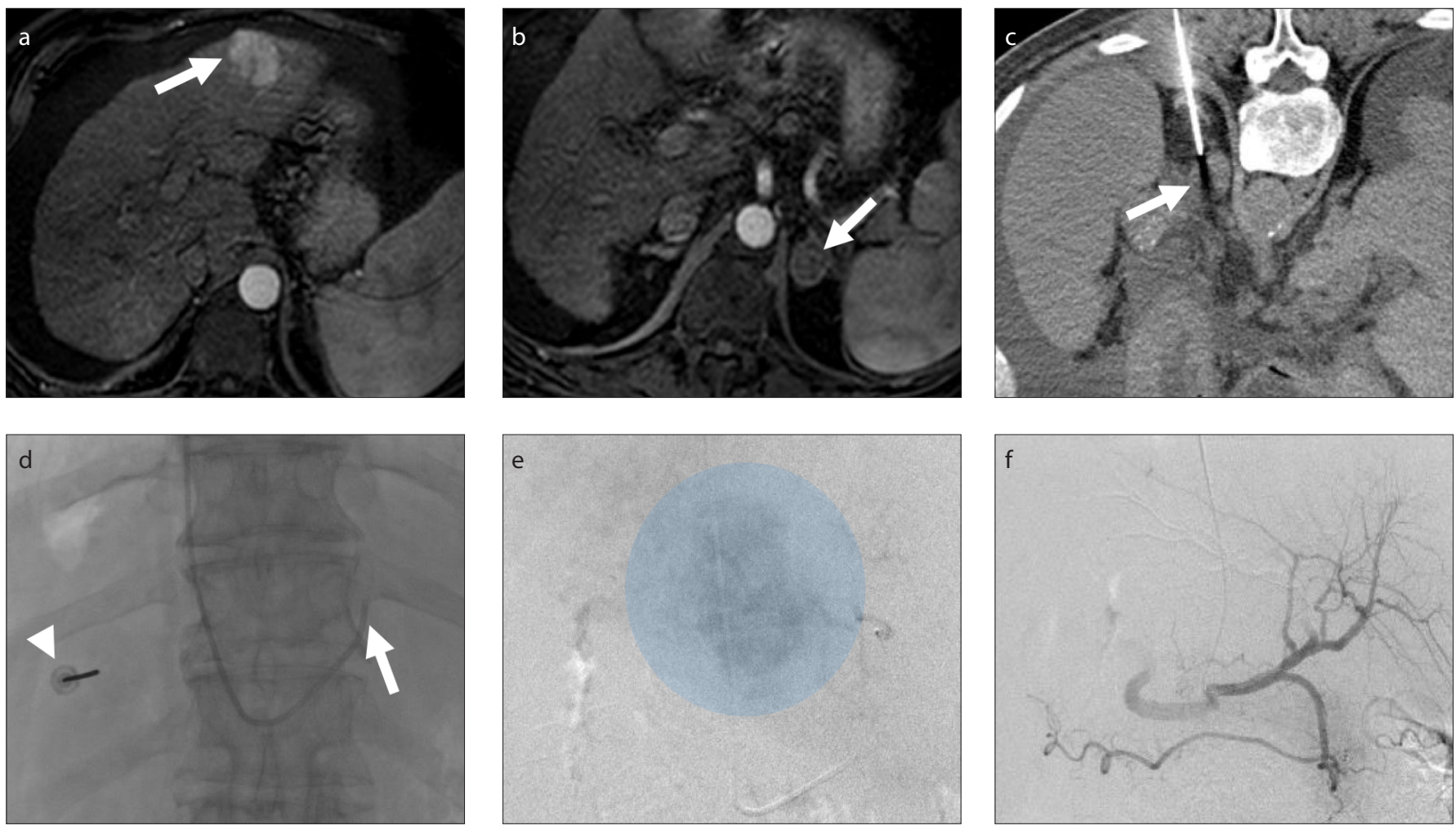

Figure 3. a-f. A 66-year-old male with cirrhosis, portal hypertension, and liver and adrenal masses. Contrast-enhanced axial magnetic resonance image (a) of the abdomen demonstrates a $4 \mathrm{~cm}$ hypervascular mass within the left lobe of the liver (arrow) compatible with hepatocellular carcinoma. Contrast-enhanced axial magnetic resonance image (b) at a slightly lower level demonstrates a $2.2 \mathrm{~cm}$ left adrenal mass (arrow). In- and out-of-phase imaging demonstrates no evidence for microscopic or macroscopic fat. Axial intraprocedural CT image (c) demonstrates a 17-gauge biopsy needle at the periphery of the adrenal mass (arrow) prior to biopsy. A diagnostic catheter is seen entering from a prone transradial approach (d) into the left hepatic artery (arrow). The biopsy introducer needle is also seen within the left adrenal mass (arrowhead). Subselective magnified diagnostic left hepatic arteriography (e) demonstrates the hypervascular mass within the left hepatic lobe. Following chemoembolization, hepatic arteriography (f) reveals the mass is appropriately devascularized.

\section{Discussion}

This study describes the utility of PTRA in performing procedures requiring single-session endovascular and percutaneous access from a posterior approach. TRA has been previously shown to be advantageous in shortening patient recovery times, reducing hospital costs, decreasing access site complications, and improving patient satisfaction $(2,3)$. Utilizing prone patient positioning may allow the operator to perform complex and innovative procedures to treat patients without the need for mid-procedure patient repositioning.

Prone patient positioning may be required for percutaneous genitourinary, retroperitoneal, pelvic, spine, and lung interventions as well as in the treatment of posteriorly located arteriovenous malformations. The combination of transarterial embolization with radiofrequency ablation has been shown to have greater efficacy in the treatment of solid renal neoplasms than either therapy alone (18-21). Oncologic interventions such as combined transarterial embolization and radiofrequen- cy ablation, have been shown to be successful using the PTRA approach with posterior percutaneous access to directly target the lesion (13). In such cases, if supine transradial or transfemoral access were used for endovascular intervention, the patient would need mid-procedure repositioning and re-preparation for subsequent percutaneous intervention. This could result in prolonged procedure time and potentially increase the risk for intraprocedural complications. Popliteal artery access is an alternative for simultaneous transarterial and posterior percutaneous approach interventions, but theoretically may have more access site complications.

In the present study, several cases of combined embolization and cryoablation of renal cell carcinoma and pelvic tumors were performed using PTRA. Additionally, prone patient positioning allowed for chemoembolization of hepatocellular carcinomas as well as biopsy of renal and other retroperitoneal or pelvic masses prior to ablative therapies. Similar access was also used to treat complex arteriovenous malformations from a prone approach. In all such cases patients reported improvement in clinical symptoms following treatment without any access-site related complications.

Two cases of foreign body retrieval from the renal collecting system were performed with prone patient positioning. In both cases embolization coils placed for arterial pseudoaneurysms had eroded from the vessel into the collecting system. In order to safely remove these, PTRA was obtained to maintain control of the previously embolized vessel in the event of hemorrhage resulting from nephroscopic removal of the coils. In one patient, PTRA proved critically necessary as glue embolization of the vessel was required after percutaneous removal of the coils due to arterial extravasation.

There are several limitations to this study. The study was performed at a single institution and included only 15 patients. PTRA was performed for a variety of procedures and without comparison to supine TRA. All cases were performed in a hybrid angiography suite offering simultaneous fluoroscopic and 

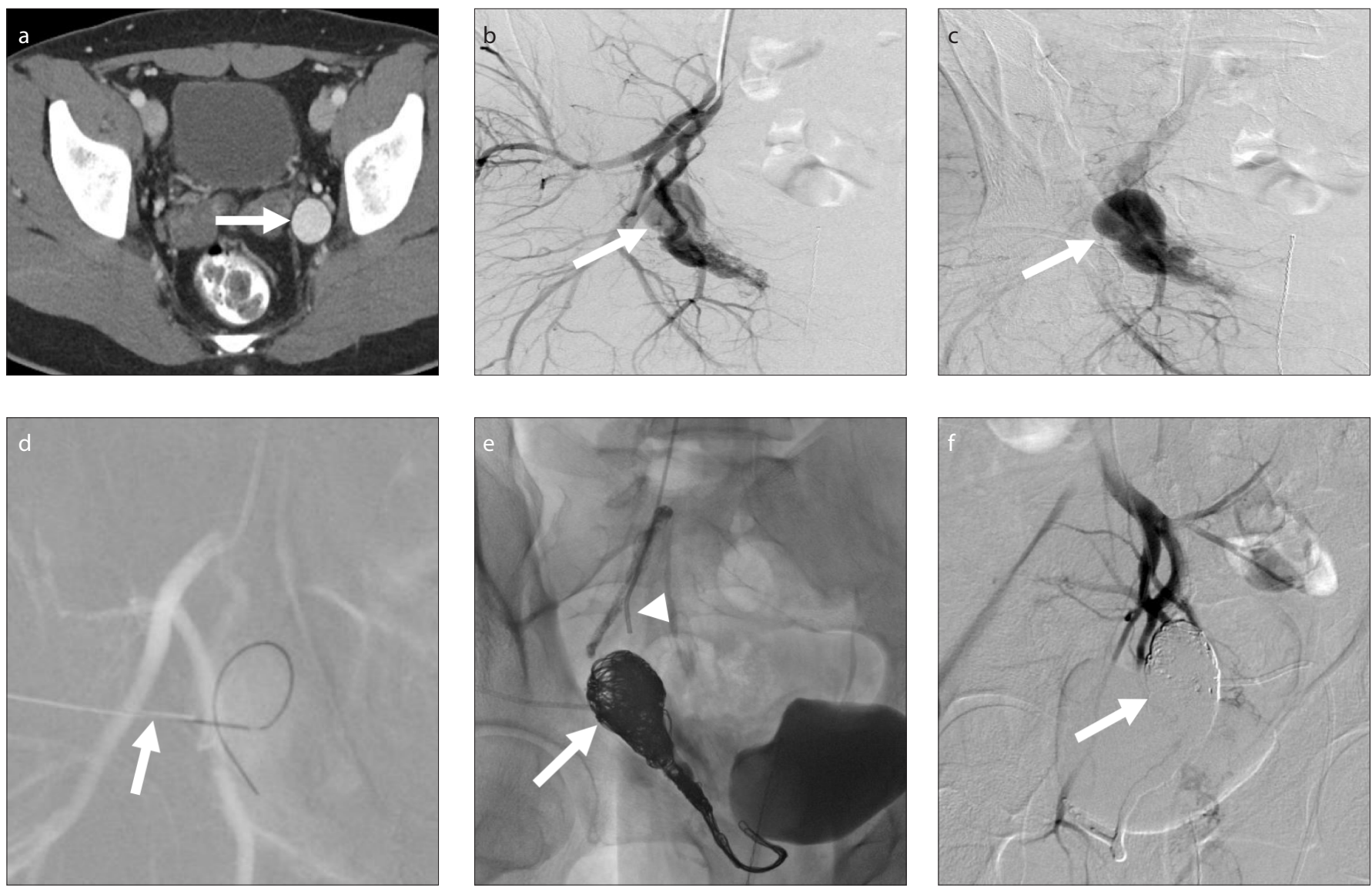

Figure 4. a-f. A 19-year-old male with pelvic arteriovenous malformation. Axial CT image (a) of the pelvis demonstrates a venous aneurysm component (arrow) of the pelvic arteriovenous malformation in the left hemipelvis. Notably, the bladder, femoral vein, and an internal iliac artery branch vessel are in close proximity if the venous aneurysm were approached from an anterior percutaneous approach. A posterior percutaneous-approach appears safer. Prone transradial access digital subtraction arteriograms $(\mathbf{b}, \mathbf{c})$ in early and late arterial phase demonstrate the feeding branch from the anterior division of the internal iliac artery. There is early and late filling of the venous aneurysm (arrows). A 21-gauge Chiba needle (d) is advanced into the venous aneurysm from a prone posterior approach (arrow) using simultaneous roadmap for guidance. A wire is coiled within the aneurysm. Direct percutaneous embolization (e) of the venous aneurysm is performed through a catheter positioned in the venous aneurysm with coils (arrow). Simultaneous embolization is performed from a transarterial approach (arrowhead). Postembolization arteriography (f) demonstrates devascularization of the pelvic arteriovenous malformation (arrow).

computed tomography capability which may limit the ability to replicate such procedures at all institutions.

In conclusion, PTRA is a technically feasible and safe method for performing combined endovascular and percutaneous interventions from a posterior-approach without the need for repositioning.

\section{Conflict of interest disclosure}

The authors declared no conflicts of interest.

\section{References}

1. Campeau L. Percutaneous radial artery approach for coronary angiography. Cathet Cardiovasc Diagn 1989; 16:3-7. [CrossRef]

2. Cooper CJ, El-Shiekh RA, Cohen DJ, et al. Effect of transradial access on quality of life and cost of cardiac catheterization: A randomized comparison. Am Heart J 1999; 138:430-436. [CrossRef]

3. Amin AP, House JA, Safley DM, et al. Costs of transradial percutaneous coronary intervention. JACC Cardiovasc Interv 2013; 6:827-834. [CrossRef]
4. Romagnoli E, Biondi-Zoccai G, Sciahbasi A, et al. Radial versus femoral randomized investigation in ST-segment elevation acute coronary syndrome: the RIFLE-STEACS (radial versus femoral randomized investigation in ST-elevation acute coronary syndrome) study. J Am Coll Cardiol 2012; 60:2481-2489. [CrossRef]

5. Mehta S, Jolly SS, Cairns J, et al. Effects of radial versus femoral artery access in patients with acute coronary syndromes with or without ST-segment elevation. J Am Coll Cardiol 2012; 60:2490-2499. [CrossRef]

6. Valgimigli M, Gagnor A, Calabró P, et al. Radial versus femoral access in patients with acute coronary syndromes undergoing invasive management: a randomised multicentre trial. Lancet 2015; 385:2465-2476. [CrossRef]

7. Roy AK, Garot P, Louvard Y, et al. Comparison of transradial vs transfemoral access for aortoiliac and femoropopliteal interventions: a single-center experience. J Endovasc Ther 2016; 23:880-888. [CrossRef]
8. Biederman DM, Marinelli $\mathrm{B}, \mathrm{O}^{\prime}$ Connor PJ, et al. Transradial access for visceral endovascular interventions in morbidly obese patients: safety and feasibility. J Vasc Access 2016; 17:256-260. [CrossRef]

9. Resnick NJ, Kim E, Patel RS, Lookstein RA, Nowakowski FS, Fischman AM. Uterine artery embolization using a transradial approach: initial experience and technique. J Vasc Interv Radiol 2014; 25:443-447. [CrossRef]

10. Bishay VL, Biederman DM, Ward TJ, et al. Transradial approach for hepatic radioembolization: initial results and technique. AJR Am J Roentgenol 2016; 207:1112-1121. [CrossRef]

11. Raghuram P, Biederman DM, Patel RS, et al. Transradial approach to noncoronary interventions: a single-center review of safety and feasibility in the first 1500 cases. J Vasc Interv Radiol 2016; 27:159-166. [CrossRef]

12. Staniloae CS, Korabathina R, Yu J, Kurian D, Coppola J. Safety and efficacy of transradial aortoiliac interventions. Catheter Cardiovasc Interv 2010; 75:659-662. [CrossRef] 
13. Chick JFB, Branach C, Majdalany BS, et al. Prone transradial catheterization for combined single-session transarterial embolization and percutaneous posterior approach cryoablation of solid neoplasms. Cardiovasc Intervent Radiol 2017; 40:1026-1032. [CrossRef]

14. Fischman AM, Swinburne NC, Patel RS. A technical guide describing the use of transradial access technique for endovascular interventions. Tech Vasc Interv Radiol 2015; 18:58-65. [CrossRef]

15. Barbeau GR, Arsenault F, Dugas L, Simard S, Larivière MM. Evaluation of the ulnopalmar arterial arches with pulse oximetry and plethysmography: comparison with the Allen's test in 1010 patients. Am Heart J 2004; 147:489-493. [CrossRef]
16. Omary RA, Bettmann MA, Cardella JF, et al. Quality improvement guidelines for the reporting and archiving of interventional radiology procedures. J Vasc Interv Radiol 2003; 14:S293S295. [CrossRef]

17. Burch EA, Shyn PB. Developing an interventional radiology online quality assurance database. J Am Coll Radiol 2017; 14:383-385. [CrossRef]

18. Peng ZW, Zhang YJ, Liang HH, Lin XJ, Guo RP, Chen MS. Recurrent hepatocellular carcinoma treated with sequential transcatheter arterial chemoembolization and RF ablation versus RF ablation alone: a prospective randomized trial. Radiology 2012; 262:689-700. [CrossRef]
19. Nakasone Y, Kawanaka K, Ikeda O, Tamura Y, Yamashita Y. Sequential combination treatment (arterial embolization and percutaneous radiofrequency) of inoperable renal cell carcinoma: single-center pilot study. Acta Radiol 2012; 53:410-414. [CrossRef]

20. Peng ZW, Chen MS. Transcatheter arterial chemoembolization combined with radiofrequency ablation for the treatment of hepatocellular carcinoma. Oncology 2013; 84 (Suppl 1):40-43. [CrossRef]

21. Liang HY, Guo QY, Sun W, et al. Sequential use of transhepatic arterial chemoembolization and bipolar radiofrequency ablation in the clinical therapy of hepatocellular carcinoma. Cancer Biother Radiopharm 2015; 30:427-432. [CrossRef] 